\title{
A BIOGRAFIA DA IMPERATRIZ LEOPOLDINA E A HISTORIA DO BRASIL (1).
}

\section{CARLOS H. OBERACKER JR.}

Segundo as afirmações do historiador Alberto Rangel o matrimônio de $\mathbf{D}$. Pedro e de $\mathbf{D}$. Leopoldina estava de antemão prejudicado por ter sido sujeito à política dinástica e em conseqüência de uma pretensa fealdade da princesa. No entanto, nem uma nem outra coisa correspondia, como julgamos ter conseguido provar, à realidade. D. Leopoldina não era uma mulher de beleza acentuada, mas por outro lado também não era feia, como não se cansa de repetir o biógrafo de D. Pedro e de sua maitresse, a Marquesa de Santos. Resolveu a arquiduquesa austríaca casar espontaneamente com D. Pedro por saber que este casamento era do agrado do pai e por acreditar, de acordo com a sua educação, que o cumprimento do desejo paterno não podia deixar de ter a bênção de Deus. No entarito, D. Leopoldina logo se enamorou ao obter o retrato do noivo e, mais ainda, quando viu o original. D. Pedro, de sua parte, correspondia ao amor de D. Leopoldina; de acordo com seu caráter leviano, no entanto, não era tão apaixonado como a mulher. O matrimônio tornou-se relativamente feliz, tomando-se em conta a grande diferença do temperamento, do caráter e da educação, até que a insidiosa infiltração de D. Domitila, posteriormente Marquesa de Santos, começou a destruir paulatinamente a boa convivência do casal.

Este resultado das nossas pesquisas não é somente importante para a compreensão da vida particular do casal, como também para a história da independência, já que as cartas e outras manifestações desta fase do casal devem ser analisadas sob esse prisma. 0 casal, vivendo então em plena harmonia, teve após a partida do rei

(1). - Carlos H. Oberacker Jr., A Imperatriz Leopoldina. Sua vida $e$ sua época. Editado pelo Conselho Federal de Cultura. Departamento de Imprensa Nacional. Rio de Janeiro. 1973. 493 pp. 
D. João VI somente um desejo: o de acertar na sua tarefa política para poder seguir quanto antes para a Europa. Aliás, já antes da revolução liberal portuguesa, tinha sido este sempre o anelo de ambos. No entanto, D. Leopoldina bem mais cedo do que D. Pedro foi convencida pelo representante austríaco, o Barão von Mareschal, de que a salvação da monarquia portuguesa poderia provir somente do Reino do Brasil. Era convicção de Mareschal que os portugueses radicados no Brasil, fossem eles naturais da América do Sul ou da Europa, não permitiriam a degradação do Brasil ao antigo estado colonial e que precisavam da monarquia para evitar o caos e para conquistar a sua equiparação, ou a sua independência. Se D. Pedro se pusesse ao lado dos brasileiros, mais de tendência monárquica do que os portugueses na Europa, poderia restabelecer a autoridade da realeza, que ela perdera na Europa, devido à pressão dos demagogos nas Cortes e, no Brasil, em consequiência da ingerência da Divisão Auxiliadora na política; e tendo D. Pedro restabelecido a autoridade monárquica no Brasil, poderia, quiçá, até tentar recuperá-la também em Portugal. D. Leopoldina compreendera, como já foi dito, esta situação do império português e, renunciando ao seu mais ardente desejo pessoal, isto é de voltar para a Europa, sacrificando-o às necessidades do Estado, tentou influenciar ainda D. Pedro para que ficasse no Brasil, desobedecendo ao parlamento português. Assim o Dia do Fico é também em parte obra sua, e não há dúvida de que desta resolução do casal dependia a unidade política das províncias sul-americanas: o Brasil nas suas dimensões de hoje.

As cartas de $\mathrm{D}$. Leopoldina desta época refutam claramente a tese de certos historiadores de que D. Pedro teria desde o começo de sua regência (ou pelo menos desde o dia 5 de junho) seguindo uma tática de fingimento, tendo sido sempre sua idéia apoderar-se do Reino do Brasil. Como então existisse entre ele e a mulher perfeita harmonia e como eles colaborassem politicamente, D. Leopoldina não podia ter comunicado nesta altura diversas vezes com satisfação, que esperava estar brevemente milhares de milhas mais perto de seus queridos. E se tivesse sido sempre esta a intenção de D. Pedro, perguntar-se-ia, porque então o esforço da princesa (dos paulistas e dos maçons) de convencer o Regente pôr-se decididamente ao lado dos autonomistas? Não, D. Pedro estava ofuscado, como mostram as suas próprias cartas, confirmadas pelas de D. Leopoldina, pelas idéias liberais e, de fato, era um adepto entusiasmado das Cortes. Da "divina constituição" esperava então como muitos outros os milagres da regeneração da nação portuguesa. $O$ príncipe herdeiro enveredou só passo por passo no caminho da independência e da separação, obrigado pela política das Cortes. Era ele, aliás, considerado, por José Bonifácio 
nas Lembranças do governo paulista e também por outros políticos como a pessoa menos interessada numa separação e, por isso, proposto como o regente indicado no reino em que não residia o rei. Assim fica ainda melhor compreensível que o Grito do Ipiranga constitui o fim da longa evolução de um ano, durante o qual D. Leopoldina, José Bonifácio e os maçons do Rio trabalhavam $D$. Pedro para que se fizesse monarca de uma monarquia separada do império português. Talvez esperasse D. Pedro, na primeira fase da regência de fato, como supõe Mareschal, que podia substituir o pai no trono, quando este, aborrecido do tratamento dispensado pelas Cortes, se retirasse para um convento. Em todo o caso fica, no entanto, confirmada a sinceridade das cartas de $\mathrm{D}$. Pedro ao pai (respectivamente às Cortes), a qual com argumentos fúteis foi contestada, pela correspondência de D. Leopoldina: quís ele, de fato, retirar-se para Portugal.

Outro problema, até hoje pouco estudado e que pode ficar esclarecido somente tomando-se em consideração a biografia de D. Leopoldina é o Grito do Ipiranga e o seu significado (2). Este sempre foi considerado isoladamente; a biografia de $\mathrm{D}$. Leopoldina mostra, no entanto, que só pode ser compreendido em função dos acontecimentos no Rio de Janeiro, A Princesa Real fora nomeada por um decreto especial substituta do Regente com os mais amplos poderes. Convocara ela, em consequiência de notícias recebidas sobre as decisões das Cortes em relação ao Brasil e a pedido de José Bonifácio de Andrada e Silva, para o dia 2 de setembro o Conselho de Estado que decidiu sob a sua presidência unanimamente a separação do Reino do Brasil do império português. De acordo com o decreto que nomeara $\mathrm{D}$. Leopoldina regente temporária, tal decisão necessitava da confirmação do Príncipe itinerante; por este motivo foi enviado ao seu encontro um mensageiro especial, levando sem dúvida um ofício referente à sessão tão importante, além das cartas particulares da princesa e de José Bonifácio, em que o destinatário foi estimulado a sancionar a resolução do Conselho de Estado. D. Pedro foi portanto dispensado da para ele tão difícil decisão de separar o Reino do Brasil do de Portugal, precisando somente ratificar uma decisão já tomada pelo orgão mais alto de seu próprio governo. O Grito do Ipiranga constitui, portanto, a ratificação de uma decisão tomada pelo Conselho de Estado sob a presidência e anuência de sua esposa. Esta resolução significava para D. Pedro ao fim e ao cabo a glória de se tornar o fundador de um novo e grande império, enquanto que a princesa a iria pagar não somente com a

(2). - Ver tambem: Carlos H. Oberacker Jr.: "O Grito do Ipiranga" - Problema que desafia os historiadores, em: Revista de História, $\mathrm{n}^{\circ}$ 92, São Paulo, 1972, pp. 411 ss. 
renúncia ao seu mais ardente desejo particular, mas sim com o desespero e a morte, pois nesta mesma viagem $D$. Pedro ia conhecer a posterior Marquesa de Santos que lhe iria furtar o coração do marido e destruir o seu matrimônio, razão da sua existência .

Sempre houve quem tentasse negar, ou pelo menos diminuir a culpa de D. Pedro em relação à morte da esposa. Esta tinha, no entanto, fundamentada de fato toda a sua existência no matrimônio com D. Pedro, a quem amava de todo o coração. Durante anos D. Leopoldina ignorou, ou melhor, fingiu ignorar para com terceiros conhecer as relações entre o marido e D. Domitila, a amante, das quais, no entanto, logo de início fora informada. Fingiu ignorar tais relações por diversos motivos, por um dever monárquico para não prejudicar a instituição da monarquia e por um motivo particular, isto é para facilitar perante o público a volta do marido. Simulava a princesa ainda não saber de nada, quando $D$. Pedro teve o mau gosto de fazer a filha de um tropeiro paulista a primeira dama da esposa e quando a elevou à viscondesa de Santos. Quando, porem, legitimou a filha espúria fazendo-a Duquesa de Goiás toda a simulação se tornou futil, fato que desanimou completamente a imperatriz, convencida de que a maitresse se aproveitava de qualquer meio sobrenatural, de um feitiço. Dor e desespero dominavam cada vez mais a sua alma extremamente sensível. A viagem à Bahia, em que o monarca deu ao público um cruel espetáculo amoral e, enfim, o "horroroso atentado", isto é o maltratamento corporal perante aquela "que é a causa de toda a minha desgraça", deram-lhe a convicção de que perdera para sempre o coração do marido e que a sua vida já não tinha mais sentido algum, já que dera a luz a um filho varão, continuador da monarquia; quando o "horroroso atentado" a prostou à cama já perdera o último gosto da vida e não fez esforço algum para sobreviver a um aborto, causada por uma doença que chamaram de "febre biliar" e a qual veio transformar-se em "febre nervosa" a que não resistiu o corpo cuja saude já se encontrava minada pelas muitas humilhações e agruras, causadas pelo próprio marido. As circunstâncias de sua morte e a servidão total do imperador à Marquesa de Santos que corrompeu (sem exagero), toda a administração do Império, contribuiram sem dúvida muito mais para a queda de $\mathrm{D}$. Pedro do que os historiadores até agora estiveram dispostos a admitir. A morte da Imperatriz constituia, e há bastantes coevos que o confitmam, de fato, o começo do fim de D. Pedro I como imperador, fim que o atingiria dentro de um só lustro. 